\title{
Accommodation of large plastic strains and defect accumulation in nanocrystalline Ni grains
}

\author{
X.L. $\mathrm{Wu}^{\mathrm{a})}$ \\ State Key Laboratory of Nonlinear Mechanics, Institute of Mechanics, Chinese Academy of Sciences, \\ Beijing 100080, China \\ E. $\mathrm{Ma}^{\mathrm{b})}$ \\ Department of Materials Science and Engineering, Johns Hopkins University, \\ Baltimore, Maryland 21218
}

(Received 22 December 2006; accepted 12 April 2007)

\begin{abstract}
A transmission electron microscopy (TEM) study has been carried out to uncover how dislocations and twins accommodate large plastic strains and accumulate in very small nanocrystalline $\mathrm{Ni}$ grains during low-temperature deformation. We illustrate dislocation patterns that suggest preferential deformation and nonuniform defect storage inside the nanocrystalline grain. Dislocations are present in individual and dipole configurations. Most dislocations are of the $60^{\circ}$ type and pile up on (111) slip planes. Various deformation responses, in the forms of dislocations and twinning, may simultaneously occur inside a nanocrystalline grain. Evidence for twin boundary migration has been obtained. The rearrangement and organization of dislocations, sometimes interacting with the twins, lead to the formation of subgrain boundaries, subdividing the nanograin into mosaic domain structures. The observation of strain (deformation)-induced refinement contrasts with the recently reported stress-assisted grain growth in nanocrystalline metals and has implications for understanding the stability and deformation behavior of these highly nonequilibrium materials.
\end{abstract}

\section{INTRODUCTION}

In plastic deformation of polycrystalline materials, microscopic strain accommodation processes are required to maintain strain continuity across the grain boundaries (GBs). In conventional coarse-grained metals, compatible strains are realized through the activities and arrangements of dislocations, which are the predominant carriers of plastic deformation. It is known that a microscopic incompatibility region may exist in the vicinity of $\mathrm{GB}$, forming a GB region micrometers wide containing high densities of dislocations. ${ }^{1,2}$ The GB region can, therefore, be more strained than the grain matrix and somewhat stronger than the matrix. The GBs may act as dislocation sources and sinks, and complex deformation structures, i.e., patterns of accumulated dislocations induced by plastic deformation, have been frequently observed in the GB region. ${ }^{1,2}$ Based on such a picture, Ashby $^{3}$ and Kocks ${ }^{4}$ proposed a composite model of plastic deformation: the deformation of each grain may be separated into a uniform deformation region in the grain

\footnotetext{
Address all correspondence to these authors.

a) e-mail: xlwu@imech.ac.cn

b) e-mail: ema@jhu.edu

DOI: $10.1557 / J M R .2007 .0279$
}

interior and a local, nonuniform deformation zone in the GB regions. A number of models invoke ideas along similar lines (e.g., Refs. 5-8), introducing concepts such as geometrically necessary dislocations near the boundaries and statistically stored dislocations in the interior.

With the advent of nanocrystalline (NC) metals, a question naturally arises as to what would happen when the grains are extremely small. Would deformation also occur in an inhomogeneous manner so as to achieve compatible plastic strains across the GBs? What is the pattern of the stored dislocations and twins, if they do get stored at all, in extremely small nanocrystalline grains? Different assumptions and predictions can be found in the literature. Some models use the concept of a grain boundary zone, deforming differently from the grain interior but not composed of dislocation structures. ${ }^{9,10}$ Many believe that, when grains are on nanoscale, GB diffusion and GB sliding are so dominant that there is not much deformation inside the grains (except occasional dislocation involvement to accommodate the GB sliding). Many papers reporting transmission electron microscopy (TEM) observations of NC grains after deformation conclude that there is little deformation debris left inside the grain (but the dislocations contributing to deformation may have all run out of the grains and mostly annihilate 
and disappear into the abundant surrounding GBs). ${ }^{11-14}$ The tiny grain can also rotate as a whole to produce and accommodate the strains. ${ }^{15,16}$ In addition, a significant fraction of atoms now sit in the GBs and can undergo atomic shuffling as the GBs shear. ${ }^{17,18}$ Finally, it was reported that several close-by nanograins would rotate and align to shear on a common shear plane, and deformation in this case involves cooperative action of a group of grains. ${ }^{19}$

None of these scenarios would lead to grain refinement resulting from the rearrangements of accumulated dislocations, which is a common consequence for conventional coarse grains subjected to large plastic deformation. ${ }^{2,8}$ Is, then, the formation of subgrain structures possible in NC grains when they are subjected to large strains; and, if yes, when does that happen and how does the process play out?

To address these questions, this study examines the deformation patterns and the defect (dislocations and twins) accumulation in NC grains, by subjecting $\mathrm{NC} \mathrm{Ni}$ to large plastic deformation. We have used electroplated $\mathrm{NC} \mathrm{Ni}$ with truly nanocrystalline grains $(\sim 25 \mathrm{~nm}$ average grain size) at the outset, to observe how $\mathrm{NC}$ grains respond to the imposed deformation. This avoids the complications associated with the use of coarse grains that decompose into nanostructures during severe plastic deformation (such as high-pressure torsion ${ }^{20}$ ), where the deformation structures observed may be formed in coarser grains during their evolution toward the nanostructure. The NC Ni was deformed using cold rolling, to strains of $\sim 46 \%$ in thickness reduction. Rolling was used because in a tensile test the NC Ni foil fails at a small strain of only a few percent, making it impossible to observe how the $\mathrm{NC}$ grains evolve at large plastic strains. We also performed the deformation at a low temperature, i.e., our cold rolling was conducted at liquid-nitrogen temperature. This low temperature suppresses dynamic recovery and facilitates the observation of defects and their accumulation (dislocations, twins, and their organization into sub-boundaries), which would otherwise annihilate and undergo depinning much faster at room temperature. ${ }^{21,22}$ The recovery process under stress could also lead to dynamic grain growth ${ }^{23-26}$ or at least require much larger strains to observe changes in defect content and resulting patterns. We performed extensive TEM examinations to seek answers to the several questions posed in the two preceding paragraphs.

In addition to the populous general high-angle GBs, we note that there are also special boundaries inside the NC grains that could contribute to, and affect, deformation. Very often the processing steps leading to the $\mathrm{NC}$ grain structure leave nanoscale twins (e.g., growth twins or annealing twins) inside the grains. ${ }^{27,28}$ The twin boundaries (TBs) would then subdivide the NC grains and intersect the GBs. TBs are also introduced into NC grains during plastic deformation when mechanical twins form. ${ }^{29-36}$ MD simulations ${ }^{37,38}$ suggest that in facecentered-cubic (fcc) metals the presence of grown-in TBs can experience TB migration (TBM) under stresses, where partial dislocations are emitted on atomic planes adjacent to the TB, resulting in TB movement perpendicular to the TB plane. This mechanism was predicted to be particularly favorable in $\mathrm{Al}$, more so than in $\mathrm{Ni}$. This difference was explained in terms of the generalized planar fault (GPF) energy curves and the relative barrier height for dislocation nucleation when the partial is nucleated on the plane adjacent to the TB. ${ }^{37,38}$ It is also known that TBs effectively block dislocation motion. However, there has been no direct experimental evidence for TBM-mediated plastic deformation in NC grains. In the following, we will provide such evidence and also examine strain accommodation in the vicinity of TBs and inside existing twins.

\section{EXPERIMENTAL PROCEDURES}

\section{A. Samples and processing}

Fully dense NC Ni sheets were procured from Goodfellow Inc. The as-received foil was $150 \mu \mathrm{m}$ thick and of $99.8 \%$ purity. The NC Ni samples of $15 \times 30 \mathrm{~mm}^{2}$ in size were deformed via cold rolling to $46 \%$ rolling strain $(\sim 14$ passes) at both room temperature (RT) and liquidnitrogen temperature (LNT). For LNT rolling, the sample was cooled in liquid nitrogen between consecutive rolling passes. The temperature was measured using a thermocouple to be about -150 and $-120{ }^{\circ} \mathrm{C}$, respectively, before and after each pass. The samples were rotated $90^{\circ}$ between consecutive passes to obtain nearly equi-axed grains. The strain rate was $\sim 10^{-2} \mathrm{~s}^{-1}$.

\section{B. TEM techniques for defect characterization}

The microstructures were examined at room temperature using a high-resolution transmission electron microscope (HRTEM), JEM2010F (JOEL Ltd., Tokyo, Japan) operated at $200 \mathrm{kV}$. The TEM specimens were prepared by conventional twin-jet polishing technique using a nitric acid-methanol solution $\left(20 \%\right.$ by volume of $\left.\mathrm{HNO}_{3}\right)$ at $-30{ }^{\circ} \mathrm{C}$. The as-received NC Ni foil was examined extensively before rolling deformation. A plan-view micrograph is shown in Fig. 1(a). The average grain size is $\sim 25$ $\mathrm{nm}$. Along the direction perpendicular to the foil plane, the grains are slightly larger due to columnar growth during electrodeposition, as seen in Fig. 1(b). But the grains are mostly $<50 \mathrm{~nm}$ in size and close to being equi-axed. After examining $\sim 30$ grains, we concluded that the presence of growth twins and dislocations is relatively low in the grain interiors for this batch of the $\mathrm{NC} \mathrm{Ni}$, as seen in enlarged view Figs. 1(c) and 1(d).

A convincing TEM identification of defects in nanocrystalline grains is a nontrivial task. The microscopy 


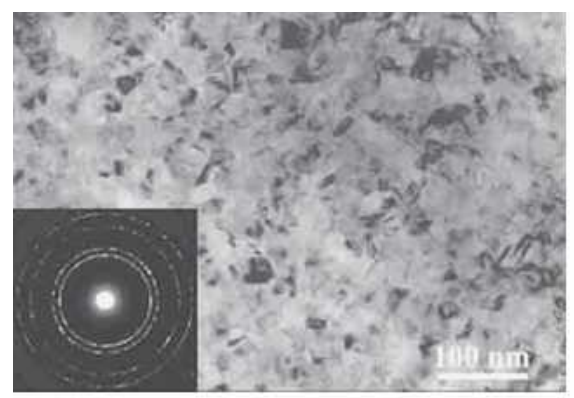

(a)

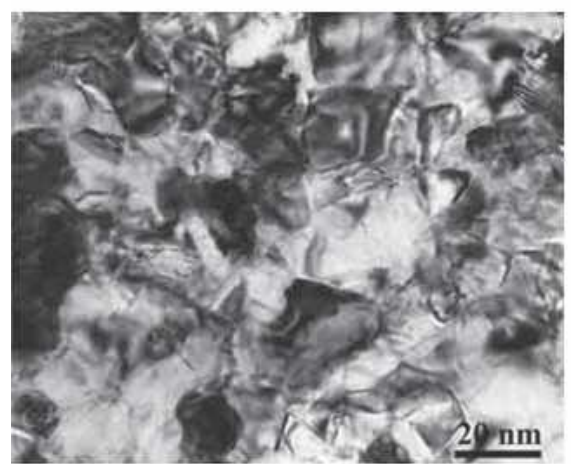

(c)

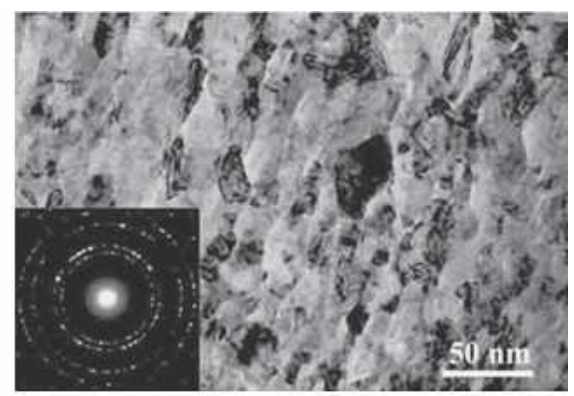

(b)

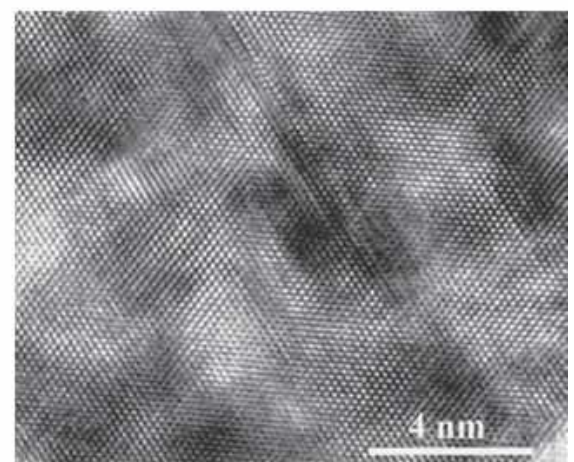

(d)

FIG. 1. Microstructures of the as-received electrodeposited NC Ni. (a) Plane-view and (b) cross-sectional TEM micrographs. Inset is the corresponding electron diffraction pattern. (c) Enlarged view and (d) HRTEM micrograph showing the lattice image of one NC grain.

technique used for this purpose therefore requires some discussion. We first note that previous ex situ conventional TEM bright-field examinations for deformed NC grains failed to show dislocation debris. ${ }^{12}$ An explanation, based on MD simulations, is that the dislocations active in deformation are all absorbed by the GBs. ${ }^{38}$ Therefore, in situ TEM was performed to observe the dynamic behavior. However, due to the global and local tilting that result from film imperfections, wrinkling, and straightening, dark-field straining experiments were unsuccessful. As a result, all of the in situ TEM observations were made in bright-field imaging mode. Ref. 14, for instance, reported dislocations for larger grains $(\sim 30 \mathrm{~nm})$, based on the abrupt and asynchronous contrast changes, different from the expected behavior of bend contours and Moiré fringes. However, the abrupt contrast changes that involved the entire grain could still result from local (i.e., grain rotation) or global tilting. In the in situ work, ${ }^{39}$ linear defects that "may be dislocations or twins" were observed, without detailed characterization.

In coarse grains, the conventional two-beam and weak-beam TEM imaging conditions are effective for characterizing the nature of dislocations. However, in $\mathrm{NC}$ grains that are only $10-30 \mathrm{~nm}$ in size with significant inherent strains, so far there has been no reported success in using these techniques for quantitative identification of individual dislocations.

This work will use extensively the HRTEM method.
For this technique, the dislocation itself, its edge or screw character, and its relation with the grain boundary, can be determined only if the dislocation is indeed present. ${ }^{15,30}$ Different from previous ex situ TEM work, our new twist is to carry out the plastic deformation at liquid-nitrogen temperature, such that some of the dislocations are retained in deformed microstructures. We note that special care is needed in using HRTEM to characterize dislocations in NC grains. ${ }^{40,41}$ The density of GBs is so high that in HRTEM images, Moiré patterns appear frequently. The strong contrast changes arising from the high density of overlapping irregularly structured GBs is not necessarily an indication of large strains caused by dislocations. Furthermore, the lattice planes can appear to be bent or interrupted and shifted due to Moiré effects rather than dislocations. Therefore, in this work, information about dislocations is obtained only from the areas without Moiré patterns.

For the cryorolled samples, both the TEM sample preparation and the HRTEM observations were performed at room temperature. But the RT procedures were limited to 20-30 min. It is possible that some evolution occurred at RT. However, given the large defect density during LNT deformation and the mobility available at low temperatures for the fcc metal, the microstructure (subgrain structure) observed is more likely a result of the evolution that happened during the low-temperature deformation. 


\section{RESULTS}

Before discussing nanocrystalline grains, we begin by first looking at deformation patterns inside ultrafine (submicron) grains. Figure 2 displays a series of TEM micrographs showing the microstructural features in ultrafine-grained $\mathrm{Ni}$ obtained via surface mechanical attrition (at RT) of coarse-grained $\mathrm{Ni}(\sim 40 \mu \mathrm{m}$ in original average grain size). Figure 2(a) is a bright-field TEM image showing that the grains have been refined to submicron sizes. Figure 2(b) is the dark-field TEM image of the grain $\mathrm{A}(\sim 500 \mathrm{~nm}$ in size) in Fig. 2(a), obtained using the (111) reflection. Dislocations with different orientations are observed, indicating the operation of different slip systems in different areas inside this grain. Interestingly, the two regions $A_{1}$ and $A_{2}$ inside do not exhibit any contrast when imaged under this condition, indicating that they are significantly misoriented. Figure 2(c) and 2(d) shows the dark-field TEM images showing these two individual areas, $\mathrm{A}_{1}$ and $\mathrm{A}_{2}$, obtained via tilting operation in the microscope. Based on the diffraction analysis, the two regions exhibit a misorientation angle, $16^{\circ}$ and $9^{\circ}$, respectively, relative to the matrix of the grain. These results demonstrate the inhomogeneous nature of the deformation pattern (and dislocation structure) within grain A. More specifically, the plastic deformation varies from place to place in the grain, concentrating more in regions (such as $A_{1}$ and $A_{2}$ ) near the $G B$. The dislocation activities lead to large misorientations between these domains and the grain matrix. As a result, gradually subgrains evolve out of these segments close to GB (such as $\mathrm{A}_{1}$ and $\mathrm{A}_{2}$ ), eventually decomposing the grain. This scenario is the same as that known for the evolution of dislocation structures and grain refinement in coarse grains. $^{1,2,8,42}$

We now move to NC Ni grains. Dislocation accumulation is known to be highly inefficient in $\mathrm{NC}$ Ni during RT deformation, due to dynamic recovery. ${ }^{11-14,34,35,43}$
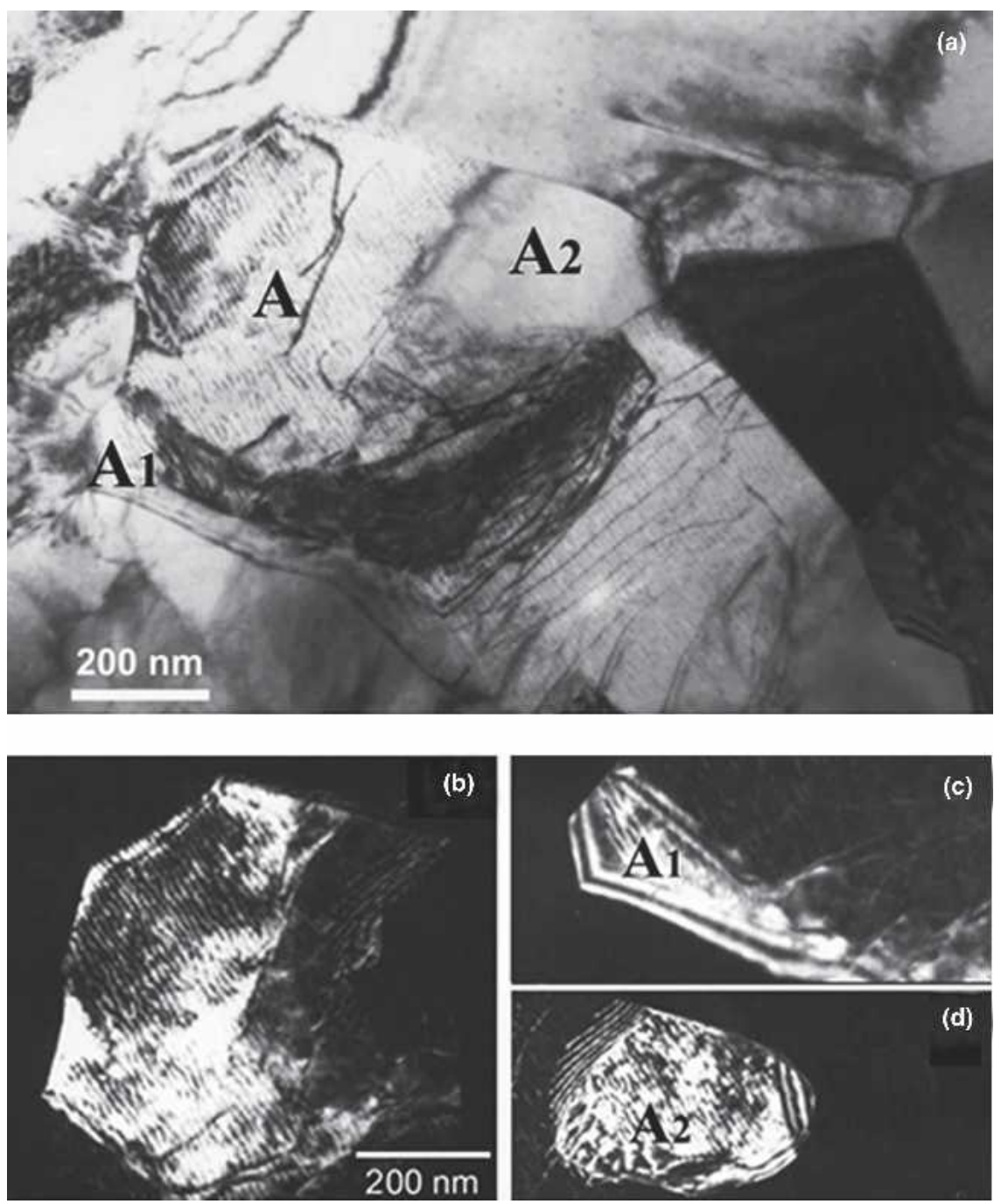

FIG. 2. TEM micrographs showing the ultrafine microstructure after mechanical attrition of coarse-grained Ni. (a) Bright-field image of a submicron grain (A) including two regions $A_{1}$ and $A_{2}$ near the grain boundary. (b-d) Dark-field images of grain $A$, regions $A_{1}$ and $A_{2}$, respectively. 
One example is shown in Fig. 3. A HRTEM micrograph shows there is no dislocation and twin in the grain interior and near the GB of a NC grain of $\sim 30 \mathrm{~nm}$ in size. Therefore, to allow ex situ observation of how defects, e.g., dislocations, evolve inside the $\mathrm{NC}$ grains in response to plastic strains, we resorted to LNT rolling to retain the defect structures, as described in the experimental section.

Interestingly, inhomogeneous deformation similar to that described in Fig. 2 was observed in NC grains after LNT deformation. Figure 4 displays a series of HRTEM micrographs showing inhomogeneous strain accommodation occurring in an $\mathrm{NC} \mathrm{Ni}$ grain $\sim 85 \mathrm{~nm}$ long and $\sim 60$ $\mathrm{nm}$ wide, as shown in the inset. Figure 4(a) is a lowmagnification HRTEM micrograph, taken with the zone axis [011]. It is an enlarged view of an area in the NC grain: from left to right, it is along the direction indicated by the arrow in the inset. The deformation structures in different regions will be described in more detail for the five white-boxed frames (1 to 5) as follows.

Figure 4(b) is the HRTEM micrograph of frame 1, showing the twin formation. ${ }^{30,33,44}$ Figure $4(\mathrm{c})$ is the HRTEM micrograph of frame 2 showing the presence of dislocation debris. Around the area labeled A, the twodimensional lattice fringes are ill-defined, indicating local distortion of crystal lattice. In contrast, the adjacent area exhibits the well-defined 2D lattice fringes. This lattice distortion is probably due to the presence of dislocation debris, similar to those observed in ultrafinegrained materials produced by severe plastic deformation. ${ }^{45}$ Several individual dislocations are indicated by Ts around area A.

For frame 3, the HRTEM micrograph obtained from the [011] zone axis in Fig. 4(d) reveals severe lattice

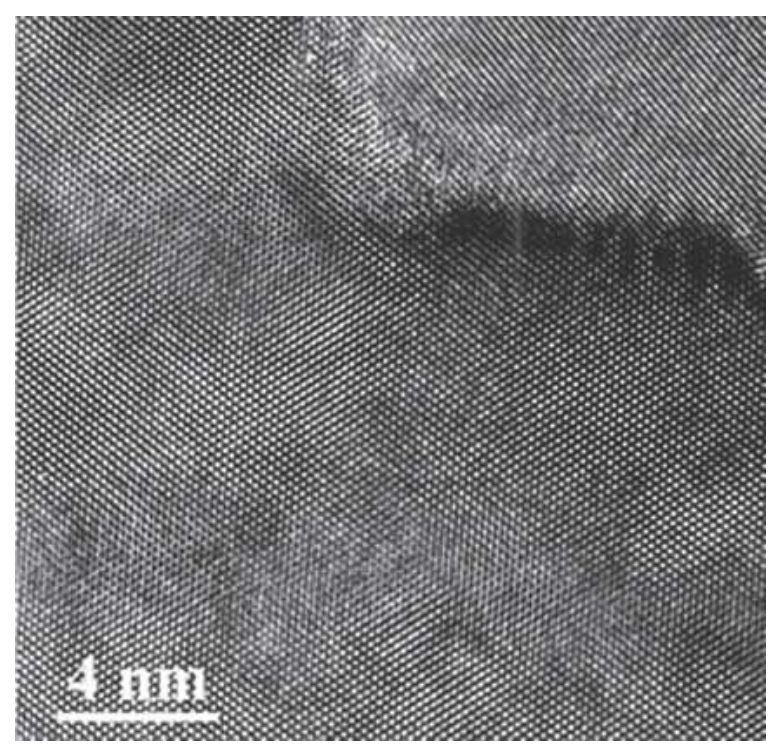

FIG. 3. HRTEM micrograph showing the lattice image of one NC grain after RT rolling. distortion, as indicated by the formation of the square lattice labeled B in contrast with the parallelogram lattice labeled A. Importantly, a number of dislocations (indicated by the $T$ symbols) are visible and stack up on the boundary between the square lattice and the parallelogram lattice. These dislocations result in the gradual tilting of (1̄11) planes as indicated by the two straight lines. Such a change of the crystallographic orientation of the (1111) planes eventually leads to the formation of the square lattice. This dislocation mechanism for the dramatic transformation of the lattice shape is schematically depicted in the inset of Fig. 4(d). In addition, there are stacking faults (SFs), indicated by arrows. The SFs are seen to be mostly within the bounds of the local area covered in this frame. A possible mechanism for the formation of such local SFs is the dissociation of dislocations rather than the emission of partial dislocations from the GBs.

Figure 4(e) displays the HRTEM micrograph of frame 4 , showing one single dislocation as well as one dipole, i.e., dislocations with opposite signs. The local dislocation density would be $3 \times 10^{16} \mathrm{~m}^{-2}$, if one simply counts the number of dislocations divided by the area in this figure (three dislocations in the $12 \mathrm{~nm} \times 8.7 \mathrm{~nm}$ area). This means that dislocations are distributed highly nonuniformly. The inset shows a Burgers circuit enclosing the dislocation core marked by a " $\top$ ". As the electron beam and the dislocation line are parallel to [011], the Burgers vector of the dislocation is determined to be $1 / 2[101]$ or $1 / 2^{1-10}$, which has an angle of $60^{\circ}$ (or $120^{\circ}$ ) with respect to the dislocation line. For this reason, the dislocation is referred to as a $60^{\circ}$ full dislocation. The $60^{\circ}$ type dislocations are glissible along the (111) planes. Their organization into a wall as seen in Fig. 4(d) leads to the formation of the square lattice. Moreover, such a $60^{\circ}$ type dislocation is easy to dissociate to extend to more than 10 atomic planes during plastic deformation. ${ }^{46}$ This is a plausible reason for the SF formation inside the grain, as seen in Fig. 4(d). Figure 4(f) presents the HRTEM micrograph of frame 5 showing the inhomogeneous dislocation pattern near the GB. The low-angle GB shows a misorientation of $\sim 6^{\circ}$, by the presence of dislocations marked by " $T$ " on the GB. In the vicinity of GB, dislocations due to the operation of two slip systems are visible. Here the density of dislocations is at least twice as high as that in the grain interior, as shown in Fig. 4(e). This indicates that GBs act as barriers to dislocation motion and sources of dislocations, and inhomogeneous deformation may occur preferentially in the GB region.

Hence, for even a single NC grain shown in Fig. 4, various types of defects are observable. Dislocations can be in the individual or dipole forms and can bundle together to induce lattice distortion and transformations. There are stacking faults and twins as well. There appear to be multiple different deformation responses for 

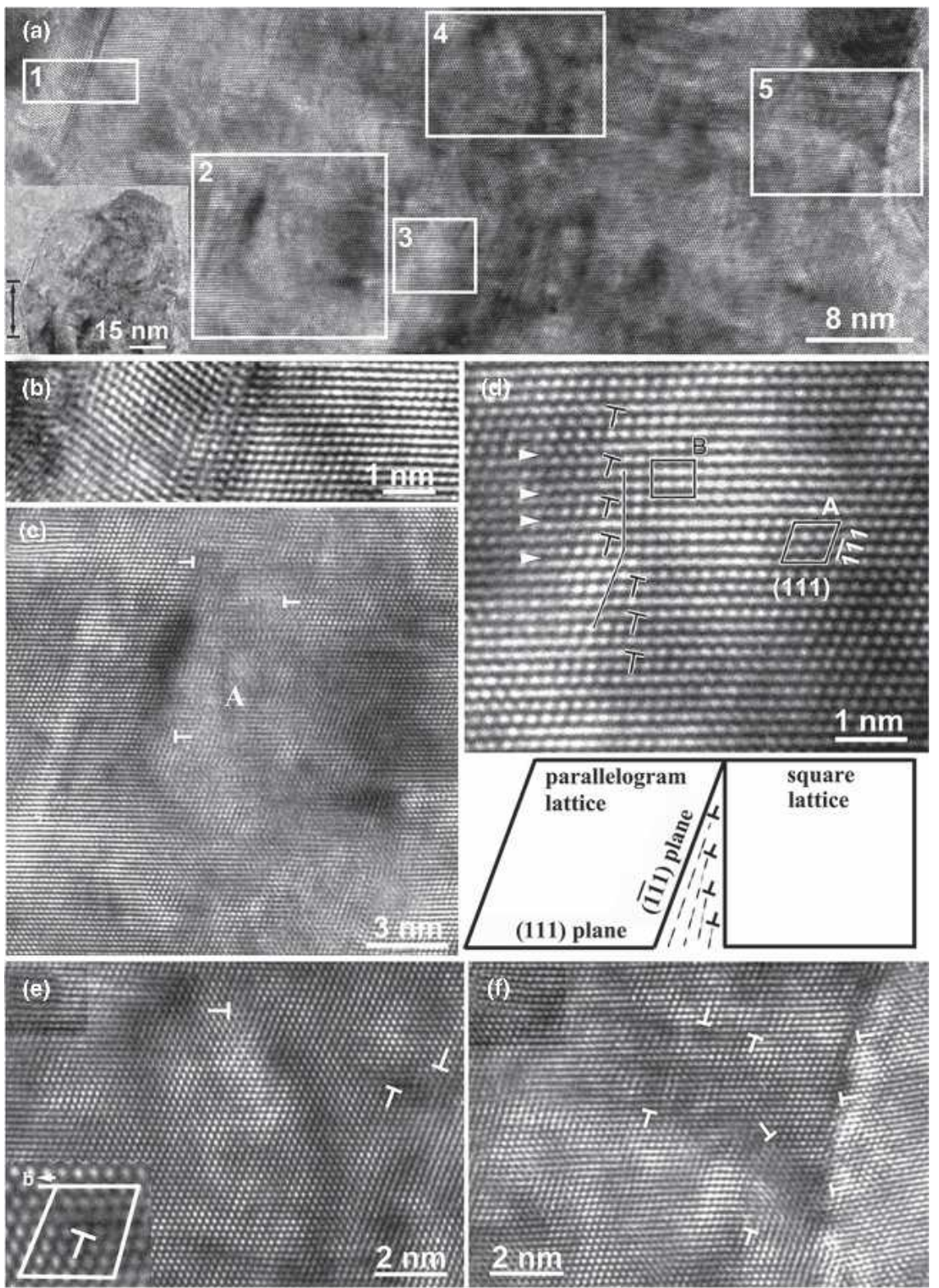

FIG. 4. Series of HRTEM micrographs showing different and inhomogeneous deformation responses in a NC grain of Ni after LNT rolling. (a) Low-magnification micrograph. Inset shows the NC grain morphology. Five frames labeled from 1 to 5 are detailed in (b) to (f), respectively: (b) formation of deformation twin near the GB; (c) examples of dislocation debris; (d) presence of severe lattice distortion (boxed areas labeled A and B indicate parallelogram and square lattice, respectively; dislocations and SFs are indicated by $T$ symbols and triangles, respectively; inset schematically illustrates how the transformation from the parallelogram lattice to the square lattice is realized through dislocations); (e) individual dislocation and dislocation dipole (inset is a Burgers circuit enclosing the dislocation core marked by a " $T$ ”); (f) dislocation accumulation near/at the grain boundary. In all figures, dislocations are indicated by $T$ symbols.

accommodating plastic strain, even in one single $\mathrm{NC}$ grain. In particular, inhomogeneous defect accumulation occurs preferentially in the vicinity of the GB.

For even smaller NC grains, evidence of dislocation accumulation and inhomogeneous deformation similar to that described in Fig. 4 is also obvious. Figure 5(a) shows an NC grain $\sim 40 \mathrm{~nm}$ in length. Three areas, in frames labeled 1-3, are selected to demonstrate inhomogeneous deformation near the GB. Figure 5(b) is the HRTEM micrograph of frame 1 showing the twin formation. Figure 5(c) is the HRTEM micrograph of frame 2. It shows the presence of dislocations with an apparently random distribution. The inset shows a Burgers circuit enclosing the dislocation core marked by a " $\top$." Clearly, the dislocation is again of the $60^{\circ}$ type. Figure 5(d) shows the HRTEM micrograph of frame 3. Different from Fig. 4(c), however, no dislocations are observed in this area. As such, Fig. 5 again shows that strain accommodation has 


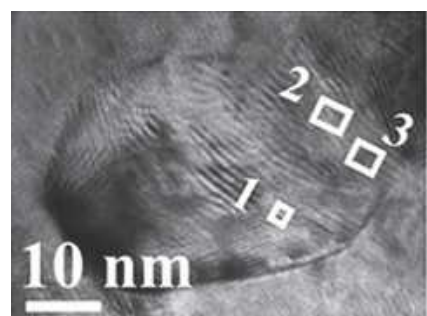

(a)
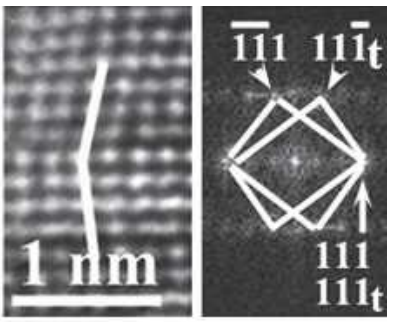

(b)

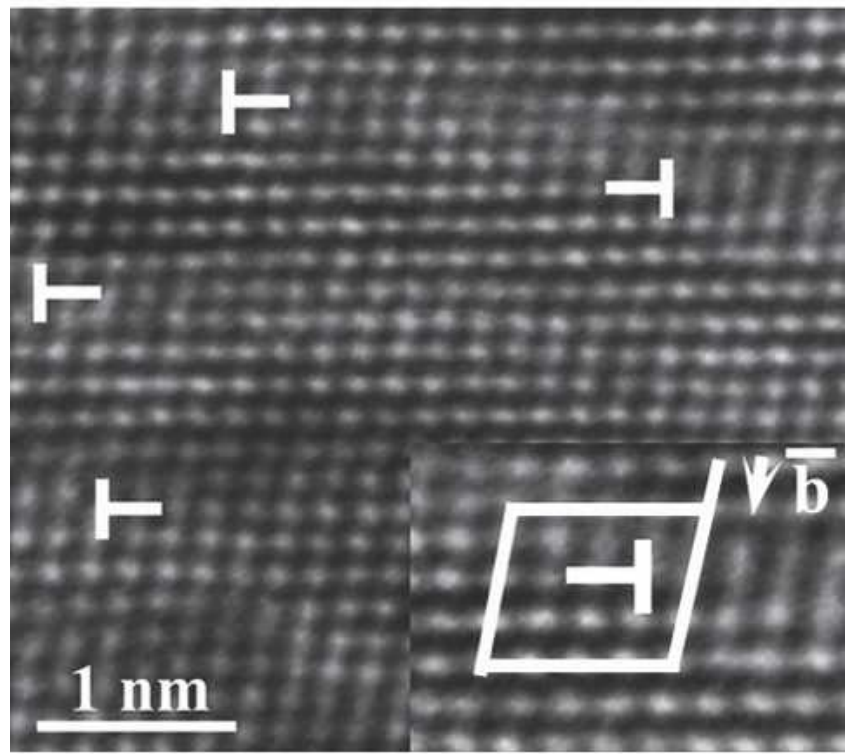

(c)

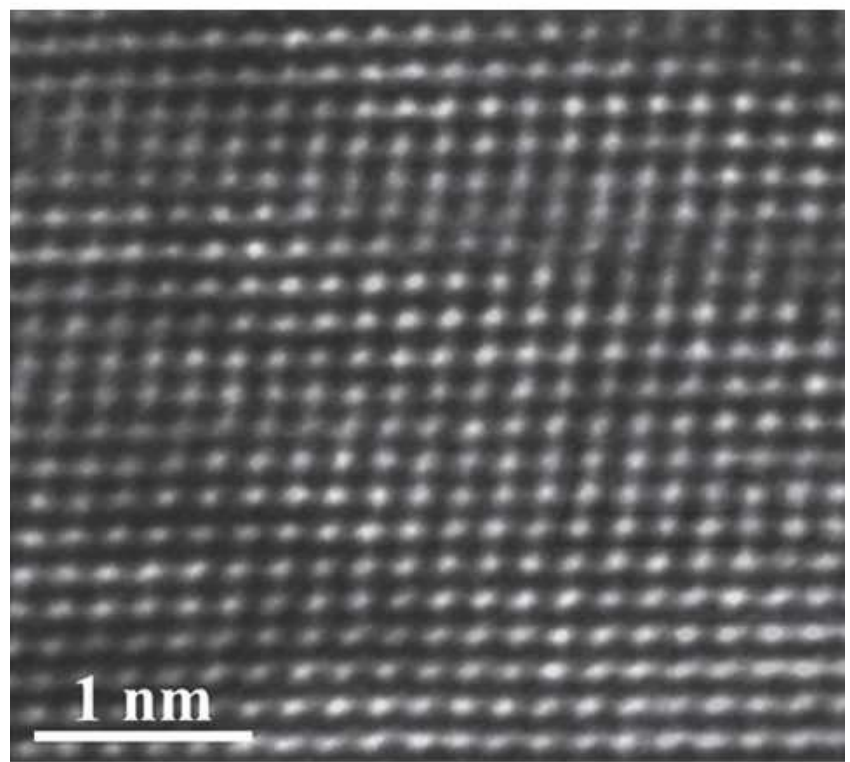

(d)

FIG. 5. (a) TEM micrograph of a NC Ni grain after LNT rolling. High-magnification image of the framed region from 1 to 3 near the grain boundary is shown in (b) to (d), respectively. (b) Deformation twin. (c) Presence of dislocations indicated by Ts. Inset is a Burgers circuit enclosing the dislocation core at the upper-right marked by a "T." (d) Perfect crystal without dislocations. multiple pathways and is inhomogeneous from place to place in the NC grain.

The formation of organized subgrain structure is more obvious in the next two TEM micrographs. Figure 6(a) shows a TEM image of a $\sim 50$-nm grain, showing several areas with clear strain contrast due to localized lattice distortion due to the dislocation cores. Interestingly, these dislocations form a dislocation subboundary as indicated by the arrow. The details are given in the HRTEM image of Fig. 6(b). This dislocation array, in fact, leads to the formation of a low-angle boundary of $\sim 4^{\circ}$ misorientation of (111) planes at two sides of the dislocation array.

Figure 7(a) shows TEM images of a still smaller NC grain, $\sim 20 \mathrm{~nm}$ in size. There seems to be a boundary, as shown by an arrow separating the whole grain into upper and lower parts. Figure 7(b) presents the HRTEM image of the boxed area in Fig. 7(a). Note the dislocations existing in the vicinity of the boundary, several of which are marked by T's. Meanwhile, dislocations are also seen near the GB. Combined with the results presented above, it is clear that dislocation formation and accumulation may form subgrain mosaic structures during plastic deformation.

The vicinity of the TBs and the interior of the twins are investigated next. Figure 8(a) is an HRTEM image showing a $\sim 25-\mathrm{nm} \mathrm{NC}$ grain. A twin plate runs across the

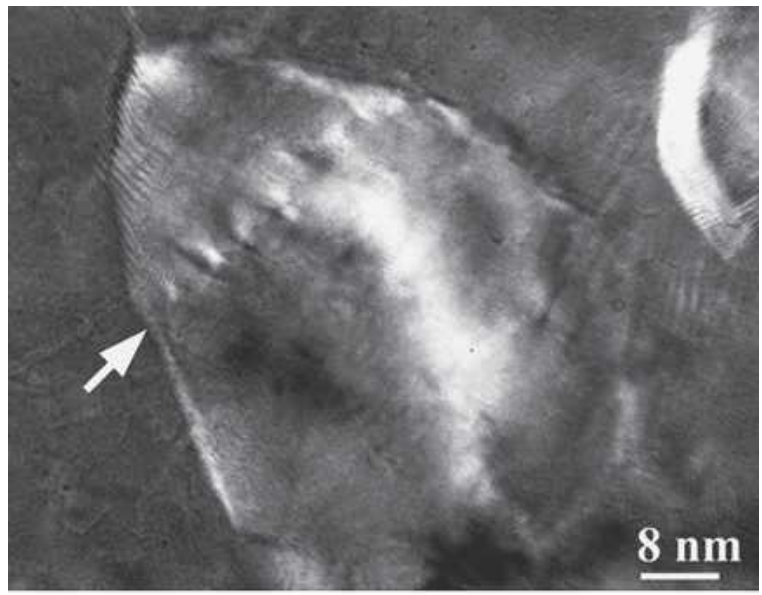

(a)

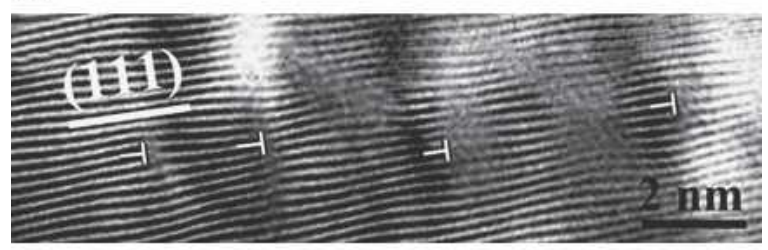

(b)

FIG. 6. (a) TEM micrograph of a NC Ni grain after LNT rolling. Arrow indicates an array of contrast due to the strains associated with dislocation cores. (b) HRTEM image of the dislocations ( $T$ symbols) that form a low-angle boundary of $\sim 4^{\circ}$ misorientation. 


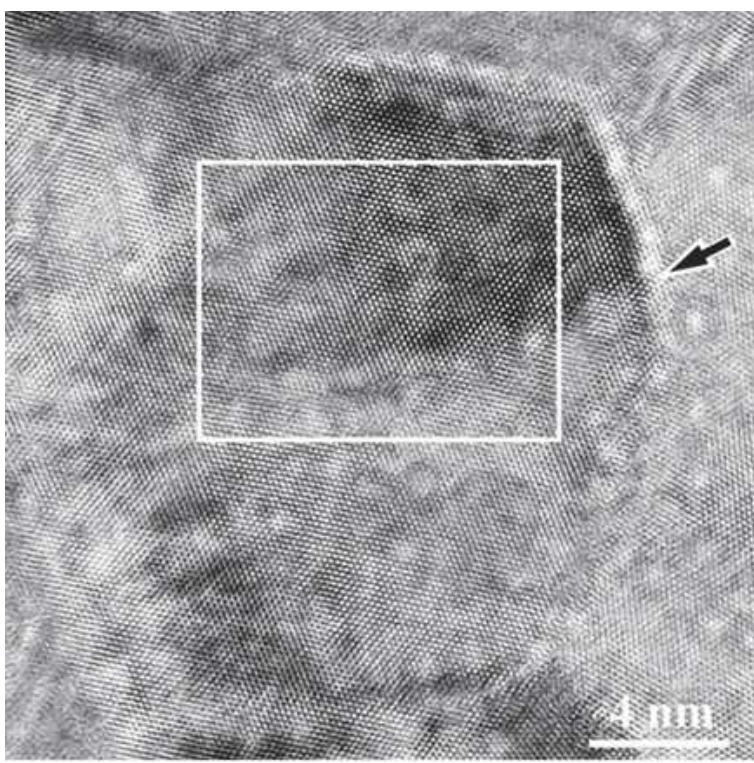

(a)

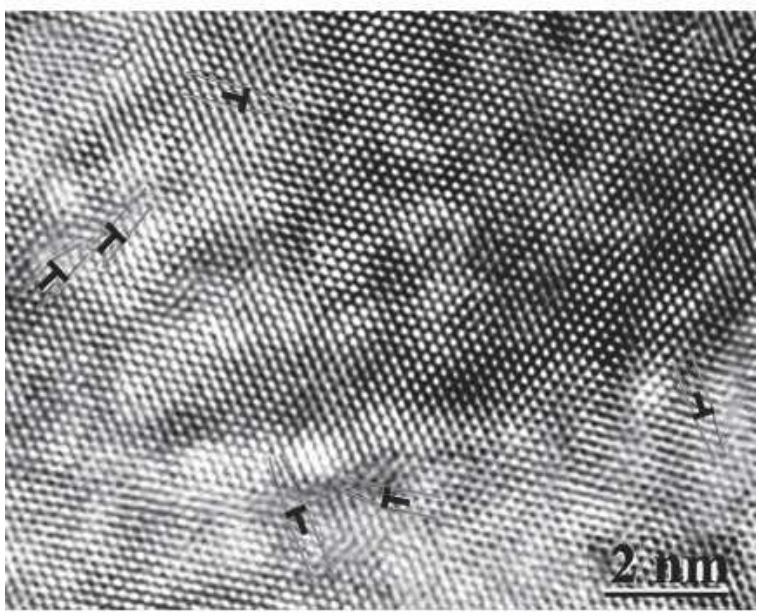

(b)

FIG. 7. (a) HRTEM image showing a NC Ni grains after LNT rolling. (b) Enlarged view of the area near the boundary. Note the dislocations indicated by $T$ symbols at or near the boundary.

entire grain with its two ends starting and finishing at the opposite GBs. Figure 8(b) is the enlarged view for the boxed area showing the left-hand side of the twin. The coherent TB is visible, and the twin plate is seven (111) planes thick. Interestingly, a full dislocation is stuck right next to the TB, indicative of the typical interplay between a twin and dislocations, i.e., TB acting as barriers to the motion of dislocations. In comparison, Fig. 8(c) reveals the detail of the other boxed area, i.e., the TB region on the far-right-hand side of the grain near the GB. The TB structure is now very different due to plastic deformation. Compared with Fig. 8(b), the twin thickness increases by four (111) planes; the new positions of the upper and lower TBs are pointed by the two triangles, respectively. Apparently, the twin widens because both of the TBs have undergone TBM during plastic deformation. Also visible is the formation of microtwins, i.e., two stacking faults on the (111) plane inside the twin, as indicated by arrows. The TBM can be explained as due to partial dislocation nucleation from GB and then slip on the plane adjacent to the TB. ${ }^{37}$ Meanwhile, additional partials emit from the GB into the twin interior, leading to the microtwin formation. The TBM result is consistent with the MD simulation ${ }^{37}$ of $\mathrm{Ni}$ deformed in a uniaxial stress state. According to the MD simulation, the TBM can be explained by the GPF energy curves. With a preexisting TB, a rigid slip on a (111) plane adjacent to the TB will result in the TB migrating one (111) plane with respect to the original configuration. The energies for the unstable stacking fault formation and for the unstable twin migration are $\gamma_{\text {usf }}$ and $\gamma_{\text {utm }}$, respectively. For Ni, the ratio $\gamma_{\mathrm{usf}} / \gamma_{\mathrm{utm}}$ is $\sim 1.3$. Therefore, TBM is favored, and both TBM and extended partial dislocations will be observed on high Schmid factor slip planes. Another mode of twin growth in $\mathrm{NC} \mathrm{Ni}$, via dynamic overlapping (or absorption) of existing stacking faults rather than new emission of partials from GB, was also reported, ${ }^{35}$ representing yet another example of preferential deformation at defects and their boundaries in NC grains.

As shown above, the mosaic domain structure may develop in NC grains upon large, inhomogeneous deformation of the dislocation slip inside the grains. Figure 9 represents another grain refinement process involving twinning and subsequent preferential deformation in its vicinity. Figure 9(a) shows a low-magnification image of the NC grain. Two frames are selected along a TB. Figure 9(b) shows the lattice structure in the area of frame 1. Clearly, this is a well-defined TB. There also exist microtwins along this local segment of $\mathrm{TB}$, similarly as in Fig. 8(c). Figure 9(c) shows the lattice structure in frame 2. The well-defined TB is visible only on the far-right side, whereas the most portions have become evidently curved and twisted due to repetitive rolling deformation. The coherent TB is destroyed, and as a result, the twinned area now changes into a grain; this indicates a grain refinement process. Another example is the small $\mathrm{NC}$ grain as shown in Fig. 10, which has a twin relation with the matrix. By comparing Fig. 10 with Fig. 9, it is possible that this small NC grain originally was also a twin part of the larger grain. As such, twinning subdivides the grain, and subsequent preferential deformation near the TB results in general high-angle GBs. Such a twinning/continued deformation/new GB formation process can be regarded as a typical refinement mechanism in NC grains.

\section{DISCUSSION}

Individual dislocation slip is inherently heterogeneous, occurring on a specific atomic plane. In this paper, the 


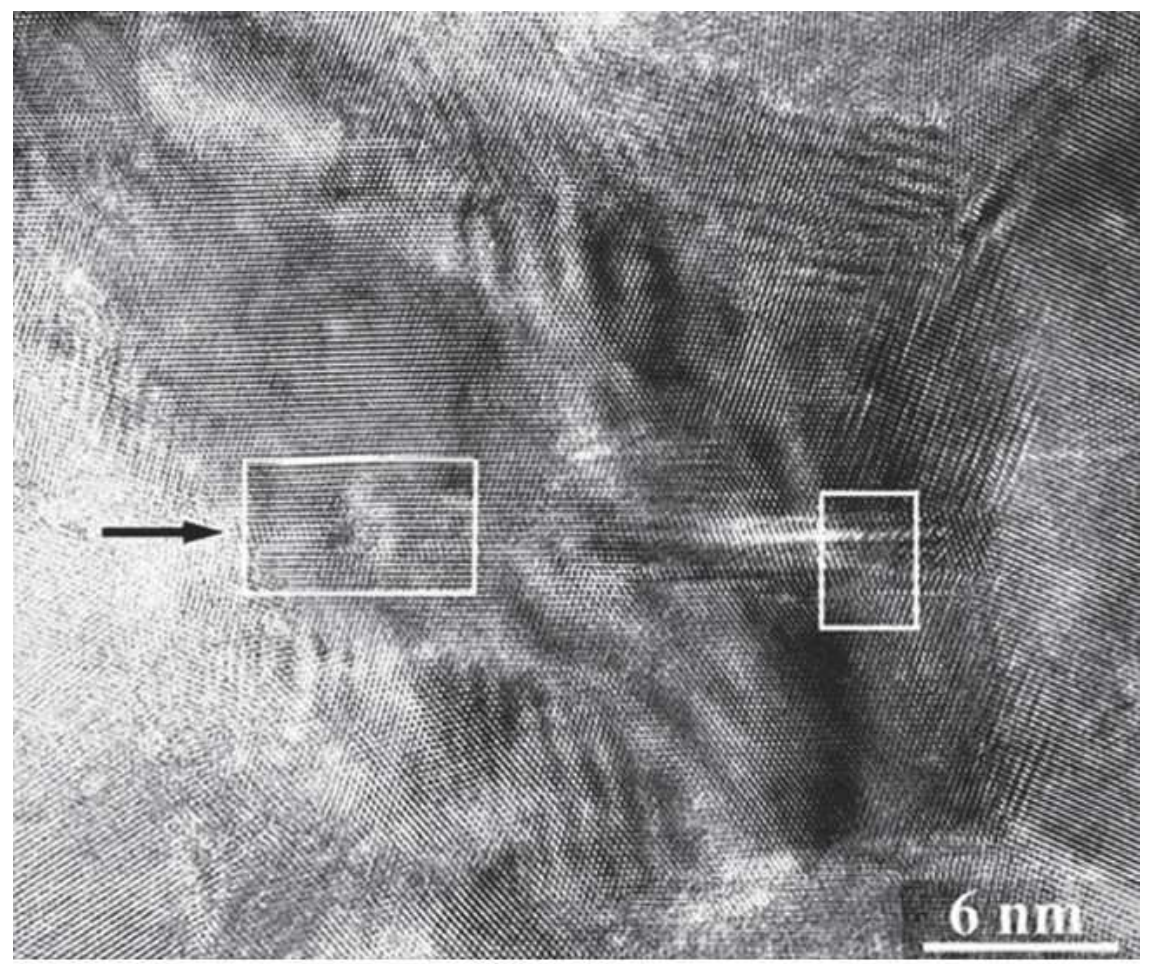

(a)

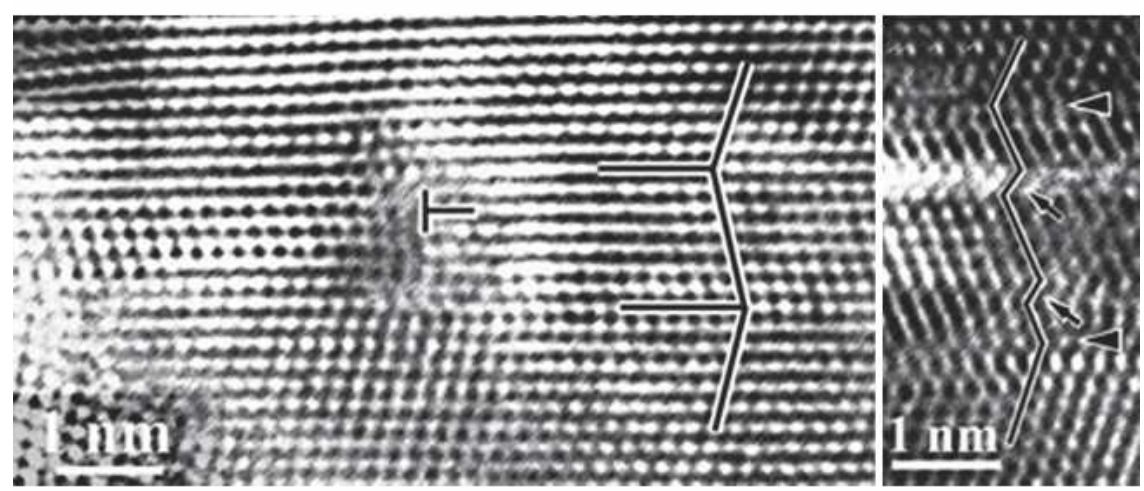

(b)

(c)

FIG. 8. (a) HRTEM showing a twin plate (indicated by arrow) running across the entire NC grain. (b) Enlarged view of the twin plate at left side showing the coherent TB; note the full dislocation in the twin plate. (c) Enlarged view of the twin plate at right side near the GB showing the twin boundary migration together with the formation of microtwins.

term "nonuniform (or inhomogeneous) deformation" refers to preferential dislocation activities and accumulation in certain regions of a grain. In what follows, we first discuss why plastic deformation tends to concentrate preferentially near GBs.

The early Sachs model ${ }^{47}$ for deformation of polycrystals suggested that the individual grains in a polycrystal deform like free single crystals (i.e., by single glide). However, because voids do not open up at the GBs during stable plastic deformation (excluding fracture), strain continuity must be maintained. This requirement was fulfilled in the Taylor theory, ${ }^{1,48}$ which suggested that all grains in the polycrystal undergo the same homogeneous strain (simultaneous slip in at least five independent slip systems) as the bulk material. A modification to the Taylor model, proposed by Kocks and Canova, ${ }^{49}$ is that strain continuity can be maintained with fewer than five slip systems for grains with special shapes (such as the flat or elongated grains that are eventually formed during large deformation) or in various regions of the grain (i.e., near GBs and surfaces). In this picture, it is proposed that the strain continuity is maintained across individual boundaries and not simultaneously for the whole grain. In other words, the GB and its vicinity are the places that plastically deform first and most. This is likely to be true also for NC grains, especially since it is at GB that 


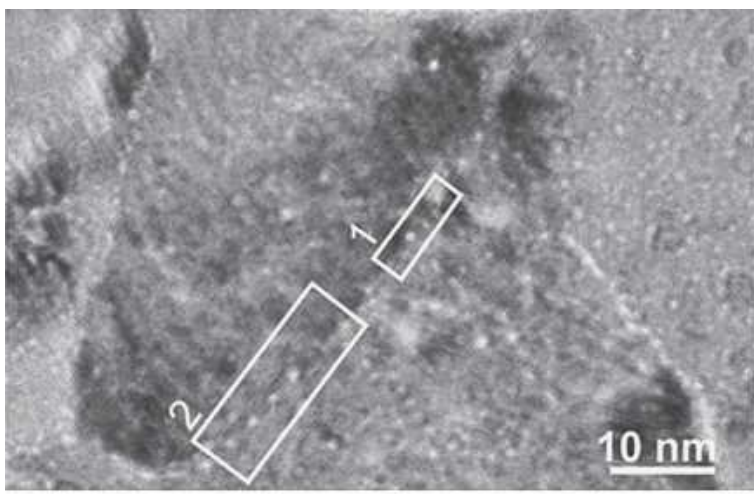

(a)

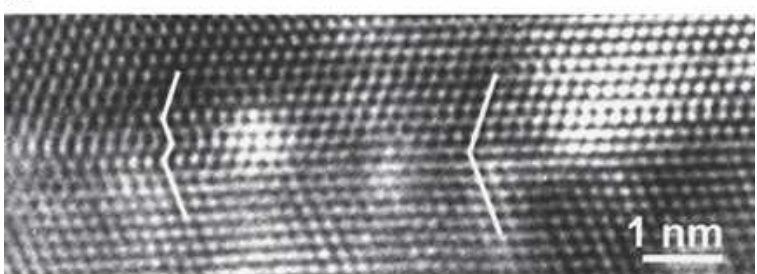

(b)

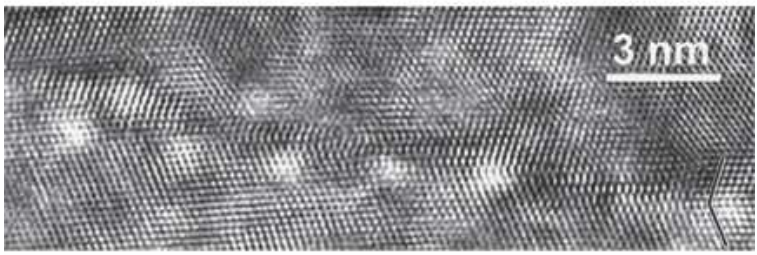

(c)

FIG. 9. (a) HRTEM image showing a NC Ni grain. (b) Enlarged view of framed area 1 showing coherent TB. (c) Enlarged view of framed area 2 showing a curved and twisted TB.

cooperating processes, such as dislocation emission, dislocation absorption, shearing, atomic shuffling, and GB diffusion take place. All these operative processes, including the dislocation activities, allow the required deformation compatibility to be satisfied. However, a more detailed mechanism for the formation of the particular structural features near GB has yet to be proposed. ${ }^{1,2}$ It is not possible to tell which of the dislocations observed are geometrically necessary ones and which are excess ones.

When a $\mathrm{NC}$ grain is subjected to an external force, an inhomogeneous state of internal stress is developed resulting from elastic anisotropy and plastic incompatibilities arising from different resolved shear stresses within the different parts of the grain. It is interesting that we observed severely nonuniform accommodation of plastic deformation inside the grains, even when we started out with very small $\mathrm{NC}$ grains. As deformation proceeds, subgrains and mosaic structures develop, much like in coarse grains where the strain-induced grain refinement has been widely studied in various conventional fcc metals, such as $\mathrm{Ni}, \mathrm{Al}$, and $\mathrm{Cu} .{ }^{8,42,50-54}$ For example, Ref. 42 suggested that a grain subdivides during deformation into

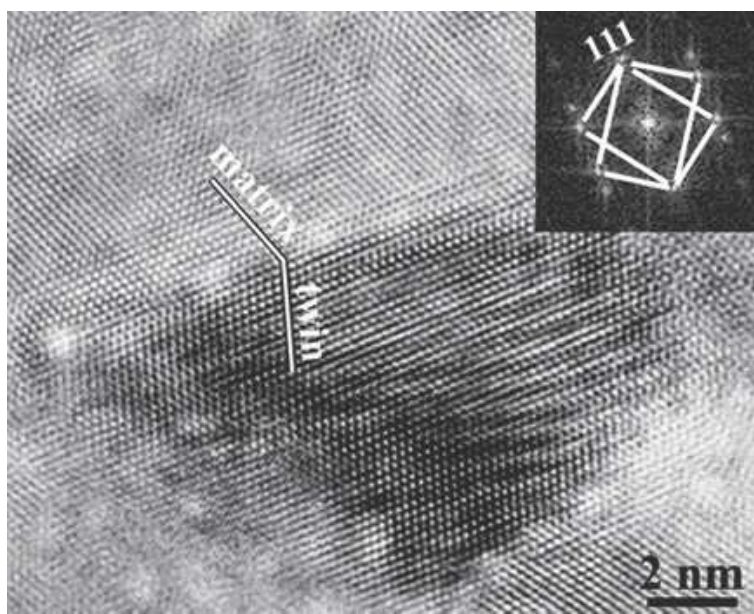

FIG. 10. HRTEM micrograph showing a NC Ni grain having twin relationship with the matrix. Inset is the Fourier-transformed diffraction pattern.

regions taking up a fraction of the grain, on a smaller and smaller scale. Each volume element is characterized by an individual combination of slip systems. The deformation pattern is quite homogeneous within each region but different from those in neighboring regions. Overall, the deformation pattern is heterogeneous, but not deforming as a whole allows the grain to better adjust to the compatibility requirements of the surrounding grains.

Dislocations are expected to remain the dominant carrier for plastic deformation in $\mathrm{NC}$ grains of the sizes in previous studies. ${ }^{33,34,55-59}$ Our TEM studies here and elsewhere ${ }^{34,36}$ have in fact identified the Burgers vectors and the character of dislocations in $\mathrm{NC} \mathrm{Ni}$. As such, we can rationalize the subdivision of the $\mathrm{NC}$ grain into volume elements by continuing to adopt the concept of slip deformation. By subdividing, an inhomogeneous deformation pattern results. Each volume element may deform via a reduced number of slip systems, with the number activated depending on the stress directions and grain orientation. At low temperatures, single slip may be the norm. ${ }^{60}$ Collectively, however, for a group of adjacent volumes, the Taylor criterion remains fulfilled. As the number of slip systems in the individual volumes of the grains is reduced, dislocation boundaries tend to form, separating such volumes.

It is normally believed that the deformation pattern is different for specimens having large or small grain size and that subdivision of grains becomes less pronounced for finer grain sizes. In fact, in many studies, the grain refinement is well characterized for the process going from coarse to ultrafine grains, but the further refinement process from ultrafine to $\mathrm{NC}$ grains and beyond (prolonged deformation of $\mathrm{NC}$ grains, as in our case) has not been systematically interrogated and understood. In particular, it is uncertain whether grain subdivision would continue upon deformation after the grain size is already 
well inside the nanocrystalline regime, say, $<30 \mathrm{~nm}$. Our results answered this question to some extent. The limiting grain size (the smallest) one can reach after very large deformation has not yet been established, but it must depend on the dynamic balance of defect accumulation (generation and reorganization) and recovery (annihilation). For a given set of deformation parameters (e.g., stress, strain rate, and temperature), there is a steady-state value of grain size. This is why NC Ni grains can grow upon RT deformation ${ }^{26}$ to a steady-state size corresponding to the particular deformation conditions (see Figure) but subdivide through defect accumulation during LNT deformation to the same overall strain. The limit of grain size one can reach is likely to be $\sim 10 \mathrm{~nm}$; pure metals are not expected to turn amorphous under ordinary deformation conditions, regardless of the plastic strains imposed.

When there are twins inside NC grains, we observed growing coherent twins via TBM and defect accumulation at the twins (many dislocations and faults/ microtwins inside the twin or near TBs). It seems that plastic deformation occurs also preferentially at twins. TB-related deformation has been modeled using MD simulations. ${ }^{37,38}$ In particular, TBM was predicted to occur for fcc NC metals. ${ }^{37}$ Our results confirm this mechanism as a way to accommodate plastic strains. Due to the stress concentration created at the intersection of a TB with a GB, the intersections may become favored sites for defect creation, such as partial dislocation emission. It is also not surprising that deformation tends to occur inside already-twinned regions. After all, the twinning response provides a means to readjust the orientations, which may allow easier operation/activation of new and additional slip/twinning systems. The partial dislocation processes leading to twinning can leave stacking faults or otherwise other defects with elevated energy, which respond more readily to applied stresses in subsequent deformation. As TBs are effective barriers to dislocation motion, it is also expected that twins and TBs will be observed as favorable locations for dislocation accumulation. Slip transmission across TBs involves constriction and dislocation reactions at TBs and deposits (partial) dislocations at the TBs. ${ }^{61}$ The TBs themselves, evolving toward noncoherence during large deformation, gradually become sources of dislocations. ${ }^{27}$

\section{CONCLUDING REMARKS}

Dislocation activities and accumulation leading to the formation of ultrafine grains have been characterized for many metals, including those that eventually evolve into nanostructures upon severe plastic deformation (e.g., Refs. 62-65). But the dislocation behavior, storage, and patterning inside already-nanocrystalline grains prepared via other (nondeformation) means had not yet been ex- amined in detail. It is clear from our study that straininduced grain subdivision does occur, even in NC grains, and the subgrain mosaic domain structures are realized via concentrated defects (dislocations, stacking faults, and twins) and their interactions in local regions. The dominant role of dislocations in mediating deformation is consistent with the indications given by the recently measured values of strain-rate sensitivity and activation volume in $\mathrm{NC} \mathrm{Ni}{ }^{55,56}$

The steady-state microstructure is found to be, as expected, dependent on deformation conditions (temperature, in our case, and the corresponding flow stress lev$\mathrm{els}^{66}$ ). While our results are for LNT deformation, the same behavior is expected for RT deformation for metals with high melting temperature (such that RT is a low homologous temperature, as LNT is for Ni) or for alloys with added elements that suppress recovery. Recent studies have emphasized the adverse effect of stress (deformation)-assisted grain growth on the stability of NC materials. ${ }^{23-26} \mathrm{We}$ look at the opposite side of the issue: stress and deformation can also keep the $\mathrm{NC}$ grain structures and even refine them. At low homologous temperatures, GB diffusion, sliding, and GB migration are reduced, especially for samples that contain a trace amount of impurities. The generation of dislocations unloads the concentrated stresses, reducing the tendency to directly couple very high stress ${ }^{25}$ to GBs and driving grain growth to accommodate the plastic strain.

Large plastic strains can be accommodated for the most part by dislocation activities and storage. We found that the vicinity of the GBs, and TBs as well, is where defects preferentially accumulate and is likely the favored place for plastic deformation. High populations of dislocations, stacking faults, and microtwins can be stored in these regions. The accommodation for compatible plastic strains is non-uniform, even for NC grains $20-50 \mathrm{~nm}$ in size. Several examples for the patterns and configurations of the dislocations residing in the $\mathrm{NC}$ grains, at or near the GBs and TBs, have been illustrated. TBM via partial dislocation emission from the GB has also been observed for the first time. Our observations point to the important role of GBs and TBs. This is consistent with the widely accepted expectations: for $\sim 20$-nm NC grains, the GBs and TBs are the high-stressconcentration regions. They are barriers to dislocations and at the same time likely dislocation sources and sinks, in lieu of the conventional intragrain Frank-Read sources distributed in the interior of the grains.

\section{ACKNOWLEDGMENTS}

X.L.Wu was supported by the National Natural Science Foundation of China (Grant Nos. 50471086 and 50571110), National Key Basic Research and Development Program of China (Grant No. 2004CB619305), the 
Chinese Academy of Sciences (Grant No. KJCX2-YWM04), and Innovation Program. E. Ma has been supported by United States National Science Foundation (DMR-0210215 and DMR-0355395).

\section{REFERENCES}

1. N. Hansen: Polycrystalline strengthening. Metall. Trans. A 16, 2167 (1985).

2. N. Hansen: Cold deformed microstructures. Mater. Sci. Technol. 6. 1039 (1990)

3. M.F. Ashby: The deformation of plastically non-homogeneous materials. Philos. Mag. 21, 399 (1970).

4. U.F. Kocks: The relation between polycrystal deformation and single crystal deformation. Metall. Trans. 1, 1121 (1970).

5. H. Mughrabi: Dislocation wall and cell structures and long-range internal stresses in deformed metal crystals. Acta Metall. 31, 1367 (1983).

6. M.A. Meyers and A. Ashworth: Model for the effect of grain size on the yield stress of metals. Philos. Mag. A 46. 737 (1982).

7. D. Kuhlmanwilsdorf and N. Hansen: Geometrically necessary, incidental and subgrain boundaries. Scripta Metall. Mater. 25. 1557 (1991).

8. D.A. Hughes and N. Hansen: Microstructural evolution in nickel during rolling to large strains. Metall. Trans. A 24, 2021 (1993).

9. R. Schwaiger, B. Moser, M. Dao, N. Chollacoop, and S. Suresh: Some critical experiments on the strain-rate sensitivity of nanocrystalline nickel. Acta Mater. 51, 5159 (2003).

10. R.A. Masumura, P.M. Hazzledine, and C.S. Pande: Yield stress of fine grained materials. Acta Mater. 46, 4527 (1998).

11. M. Legros, B.R. Elliott, M.N. Rittner, J.R. Weertman, and K.J. Hemker: Microsample tensile testing of nanocrystalline metals. Philos. Mag. A 80, 1017 (2000).

12. F. Dalla Torre, M. Victoria, and H. Van Swygenhoven: Nanocrystalline electrodeposited Ni: Microstructure and tensile properties. Acta Mater. 50, 3957 (2002).

13. K.S. Kumar, S. Suresh, M.F. Chisholm, J.A. Horton, and P. Wang: Deformation of electrodeposited nanocrystalline nickel. Acta Mater. 51, 387 (2003)

14. R.C. Hugo, H. Kung, J.R. Weertman, R. Mitra, J.A. Knapp, and D.M. Follstaedt: In-situ TEM tensile testing of DC magnetron sputtered and pulsed laser deposited Ni thin films. Acta Mater. 51, 1937 (2003).

15. Z. Shan, E.A. Stach, J.M.K. Wiezorek, J.A. Knapp, D.M. Follstaedt, and S.X. Mao: Grain boundary-mediated plasticity in nanocrystalline nickel. Science 305, 654 (2004).

16. M. Ke, S.A. Hackney, W.W. Milligan, and E.C. Aifantis: Observation and measurement of grain rotation and plastic strain in nanostructured metal thin films. Nanostruct. Mater. 5, 689 (1995).

17. A. Hasnaoui, H. Van Swygenhoven, and P.M. Derlet: Cooperative processes during plastic deformation in nanocrystalline fcc metals: A molecular dynamics simulation. Phvs. Rev. B 66, 184112 $\underline{(2002)}$.

18. P.M. Derlet, A. Hasnaoui, and H. Van Swygenhoven: Atomistic simulations as guidance to experiments. Scripta Mater. 49,629 $\underline{(2003)}$.

19. A. Hasnaoui, H. Van Swygenhoven, and P.M. Derlet: Dimples on nanocrystalline fracture surfaces as evidence for shear plane formation. Science 300, 1550 (2003).

20. X.Z. Liao, F. Zhou, E.J. Lavernia, D.W. He, and Y.T. Zhu: Deformation twins in nanocrystalline Al. Appl. Phvs. Lett. 83, 5062 $(2003)$.

21. Y.M. Wang and E. Ma: Temperature and strain rate effects on the strength and ductility of nanostructured copper. Appl. Phvs. Lett. 83, 3165 (2003).

22. H. Van Swygenhoven, P.M. Derlet, and A.G. Frøseth: Nucleation and propagation of dislocations in nanocrystalline fcc metals. Acta Mater. 54, 1975 (2006)

23. K. Zhang, J.W. Weertman, and J.A. Eastman: The influence of time, temperature, and grain size on indentation creep in highpurity nanocrystalline and ultrafine grain copper. Appl. Phvs. Lett. 85, 5197 (2004).

24. M. Jin, A.M. Minor, E.A. Stach, and J.W. Jr., Morris. Direct observation of deformation-induced grain growth during the nanoindentation of ultrafine-grained $\mathrm{Al}$ at room temperature. Acta Mater. 52, 5381 (2004).

25. D.S. Gianola, S. Van Petegem, M. Legros, S. Brandstetter, H. Van Swygenhoven, and K.J. Hemker: Stress-assisted discontinuous grain growth and its effect on the deformation behavior of nanocrystalline aluminum thin films. Acta Mater. 54, 2253 (2006).

26. X.Z. Liao, A.R. Kilmametov, R.Z. Valiev, H.S. Gao, X.D. Li, A.K. Mukherjee, J.F. Bingert, and Y.T.T. Zhu: High-pressure torsion-induced grain growth in electrodeposited nanocrystalline Ni. Appl. Phvs. Lett. 88, 021909 (2006)

27. E. Ma, Y.M. Wang, Q.H. Lu, M.L. Sui, L. Lu, and K. Lu: Strain hardening and large tensile elongation in ultrahigh-strength nanotwinned copper. Appl. Phvs. Lett. 85, 4932 (2004).

28. L. Lu, R. Schwaiger, Z.W. Shan, M. Dao, K. Lu, and S. Suresh Nano-sized twins induce high rate sensitivity of flow stress in pure copper. Acta Mater. 53, 2169 (2005).

29. M.W. Chen, E. Ma, K.J. Hemker, H.W. Sheng, Y.M. Wang, and $\mathrm{X}$. Cheng: Deformation twinning in nanocrystalline aluminum. Science 300, 1275 (2003).

30. H. Rosner, J. Markmann, and J. Weissmuller: Deformation twinning in nanocrystalline Pd. Philos. Mag. Lett. 84, 321 (2004).

31. X.Z. Liao, F. Zhou, E.J. Lavernia, D.W. He, and Y.T. Zhu: Deformation mechanism in nanocrystalline $\mathrm{Al}$ : Partial dislocation slip. Appl. Phvs. Lett. 83, 632 (2003).

32. X.Z. Liao, Y.H. Zhao, S.G. Srinivasan, Y.T. Zhu, R.Z. Valiev, and D.V. Gunderov: Deformation twinning in nanocrystalline copper at room temperature and low strain rate. Appl. Phvs. Lett. 84, 592 (2004).

33. X.L. Wu, N. Tao, Y. Hong, J. Lu, and K. Lu: $\gamma-\epsilon$ Martensite transformation and twinning deformation in fcc cobalt during surface mechanical attrition treatment. Scripta Mater. 52, 547 (2005).

34. X.L. Wu, Y.T. Zhu, M.W. Chen, and E. Ma: Twinning and stacking fault formation during tensile deformation of nanocrystalline Ni. Scripta Mater. 54, 1685 (2006).

35. X.L. Wu and E. Ma: Deformation twinning mechanisms in nanocrystalline Ni. Appl. Phvs. Lett. 88, 061905 (2006).

36. X.L. Wu, Y.T. Zhu, and E. Ma: Predictions for partialdislocation-mediated processes in nanocrystalline Ni by generalized planar fault energy curves: An experimental evaluation. Appl. Phvs. Lett. 88, 121905 (2006).

37. A.G. Frøseth, P.M. Derlet, and H. Van Swygenhoven: Grown-in twin boundaries affecting deformation mechanisms in nc-metals. Appl. Phvs. Lett. 85, 5863 (2004).

38. A.G. Frøseth, H. Van Swygenhoven, and P.M. Derlet: The influence of twins on the mechanical properties of nc-Al. Acta Mater. 52, 2259 (2004).

39. W.W. Milligan, S.A. Hackney, M. Ke, and E.C. Aifantis: In situ studies of deformation and fracture in nanophase materials. Nanostruct. Mater. 2, 267 (1993).

40. C. Rentenberger, T. Waitz, and H.P. Karnthaler: HRTEM analysis of nanostructured alloys processed by severe plastic deformation. Scripta Mater. 51, 789 (2004). 
41. D.B. Williams and C.B. Carter: Transmission Electron Microscopy, III: Imaging. A Textbook for Materials Science (Plenum Press, New York, 1996), p. 444.

42. D.A. Hughes and N. Hansen: Microstructure and strength of nickel at large strains. Acta Mater. 48, 2985 (2000).

43. Z. Budrovic, H. Van Swygenhoven, P.M. Derlet, S. Van Petegem, and B. Schmitt: Plastic deformation with reversible peak broadening in nanocrystalline nickel. Science 304, 273 (2004).

44. V. Yamakov, D. Wolf, S.R. Phillpot, and H. Gleiter: Deformation twinning in nanocrystalline $\mathrm{Al}$ by molecular-dynamics simulation. Acta Mater. 50, 5005 (2002).

45. Z. Horita, D.J. Smith, M. Nemoto, R.Z. Valiev, and T.G. Langdon: Observations of grain boundary structure in submicrometergrained $\mathrm{Cu}$ and $\mathrm{Ni}$ using high-resolution electron microscopy. J. Mater. Res. 13, 446 (1998)

46. J.Y. Huang, Y.T. Zhu, H. Jiang, and T.C. Lowe: Microstructures and dislocation configurations in nanostructured $\mathrm{Cu}$ processed by repetitive corrugation and straightening. Acta Mater. 49, 1497 (2001).

47. G.Z. Sachs: The plastic deformation mode of polycrystals. Z. Verein Deut. Ing. 72, 734 (1928).

48. G.I. Taylor: Plastic strain in metals. J. Inst. Met. 62, 307 (1938).

49. U.F. Kocks and G.R. Canova: In Proc. Conf. Deformation of Polycrystals: Mechanisms and Microstructures, Ris $\emptyset, 1981$, (Ris $\emptyset$ National Laboratory, Roskilde), pp. 35-44.

50. X. Zhang, H. Wang, J. Narayan, and C.C. Koch: Evidence for the formation mechanism of nanoscale microstructures in cryomilled Zn powder. Acta Mater. 49, 1319 (2001).

51. Y. Iwahashi, Z. Horita, M. Nemoto, and T.G. Langdon: The process of grain refinement in ECAP. Acta Mater. 46, 3317 (1998).

52. X. Wu, N. Tao, Y. Hong, B. Xu, J. Lu, and K. Lu: Microstructure and evolution of mechanically-induced ultrafine grain in surface layer of Al-alloy subjected to USSP. Acta Mater. 50, 2075 (2002).

53. Y.T. Zhu, J.Y. Huang, J. Gubicza, T. Ungar, Y.M. Wang, E. Ma, and R.Z. Valiev: Nanostructures in Ti processed by severe plastic deformation. J. Mater. Res. 18, 1908 (2003).

54. Y.M. Wang, M.W. Chen, H.W. Sheng, and E. Ma: Nanocrystal- line grain structures developed in commercial purity $\mathrm{Cu}$ by lowtemperature cold rolling. J. Mater. Res. 17, 3004 (2002).

55. Y.M. Wang and E. Ma: On the origin of ultrahigh cryogenic strength of nanocrystalline metals. Appl. Phvs. Lett. 85, 2750 (2004).

56. Q. Wei, S. Cheng, K.T. Ramesh, and E. Ma: Effect of nanocrystalline and ultrafine grain sizes on the strain rate sensitivity and activation volume: fcc versus bcc metals. Mater. Sci. Eng.. A $\mathbf{3 8 1}$ 71 (2004).

57. K.M. Youssef, R.O. Scattergood, K.L. Murty, J.A. Horton, and C.C. Koch: Ultrahigh strength and high ductility of bulk nanocrystalline copper. Appl. Phvs. Lett. 87, 091904 (2005).

58. X.L. Wu and E. Ma: Dislocations in nanocrystalline grains. Appl. Phvs. Lett. 88, 231911 (2006).

59. R. Mitra, W.A. Chiou, and J.R. Weertman, In-situ TEM study of deformation mechanisms of sputtered free-standing nanocrystalline nickel films. J. Mater. Res. 19. 1029 (2004).

60. L. Hollang, E. Hieckmann, D. Brunner, C. Holste, and W. Skrotzki: Scaling effects in the plasticity of nickel. Mater. Sci. Eng., A 424(1-2), 138 (2006).

61. Z.H. Jin, P. Gumbsch, E. Ma, K. Albe, K. Lu, H. Hahn, and H. Gleiter: The interaction mechanism of screw dislocations with coherent twin boundaries in different face-centred cubic metals. Scripta Mater. 54, 1163 (2006).

62. D.A. Hughes and N. Hansen: Graded nanostructures produced by sliding and exhibiting universal behavior. Phvs. Rev. Lett. 87. 135503 (2001).

63. L. He and E. Ma: Processing and microhardness of bulk $\mathrm{Cu}-\mathrm{Fe}$ nanocomposites. Nanostruct. Mater. 7, 327 (1996).

64. H.W. Sheng, K. Lu, and E. Ma: Melting and freezing behavior of embedded nanoparticles in ball-milled Al-10wt $\% \mathrm{M}(\mathrm{M}=\mathrm{In}, \mathrm{Sn}$, $\mathrm{Bi}, \mathrm{Cd}, \mathrm{Pb}$ ) mixtures. Acta Mater. 46, 5195 (1998).

65. Y.M. Wang, K. Wang, D. Pan, K. Lu, K.J. Hemker, and E. Ma: Microsample tensile testing of nanocrystalline copper. Scripta Mater. 48, 1581 (2003).

66. Y.M. Wang and E. Ma: Strain hardening, strain rate sensitivity, and ductility of nanostructured metals. Mater. Sci. Eng. A 375-377, 46 (2004). 